\title{
ノッチフイルタを用いたサーボ系設計手法と 柔軟ア一ムの位置決め制御への応用 \\ Design of Servo Systems Based on Notch Filter and Its Application to Positioning Control of Flexible Arm
}

\section{直江 芳樹 (名工大) 正 森 貴彦 (岐阜高専) 不破 勝彦 (名工大) 神藤 久 (名工大)}

Yoshiki NAOE, Nagoya Institute of Technology, Gokisocho, Showa-ku, Nagoya, Aichi

Takahiko MORI, Gifu National College of Technology

Katsuhiko FUWA, Nagoya Institute of Technology

Hisashi KANDO, Nagoya Institute of Technology

Key Words : Notch Filter, Servo System, Flexible Arm, Positioning Control

\section{1 はじめに}

筆者ら㹥に, 森田らが提案した周波数依存型最適サー ボ系 (1) の構造を踏まえ, 前置フィルタの特性劣化を改善し, 制振制と過渡特性の向上を目的とするノッチフィルタを用い たサーボ系設計手法を提案した ${ }^{(2)}$. 具体的には, 状態フィー ドバックループと積分器ループにおいて, 所望のノッチフィ ルタの構造を与え, 閉ループ極の配置とは無関係に, 実現さ れる前置フィルタの極を所望のものに配置した. しかし，ノッ チフィルタを用いる場合, フィードバックゲインを求める連 立方程式が不能になる問題が起こり，筆者らが用いた最小 2 乗近似解のなかの最小ノルムをもつもので山，厳密な極配置 が困難であった。

そこで, 本稿では, 上記の問題を解決し, 極配置が厳密に 指定できる様な設計手法を提案する.

\section{2 ノッチフィルタを用いたサーボ系の設計}

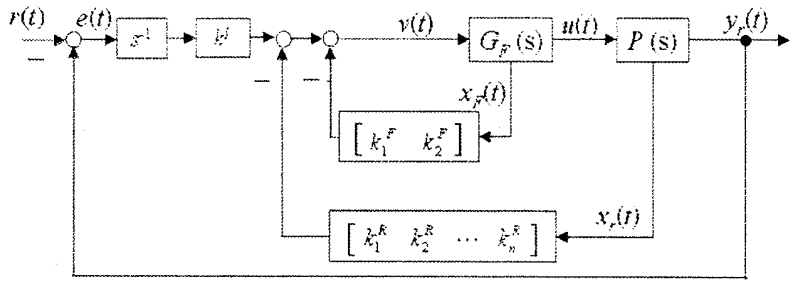

Fig.1 Block diagram of proposed control system

Fig.1 に提案するサーボ系のブロック線図を示す，制御対 象 $P(s)$ の状態空間モデルを次のように与える.

$$
\left\{\begin{array}{l}
\dot{x}_{r}(t)=\bar{A}_{r} x_{r}(t)+\bar{B}_{r} u(t) \\
y_{r}(t)=\bar{C}_{r} x_{r}(t)
\end{array}\right.
$$

ただし, 状態変数, 制御入力, そして制御量法各々 $x_{r}(t) \in R^{n}$ $, u(t) \in R, y_{r}(t) \in R$ とする. また各係数行列は

$$
\begin{aligned}
\bar{A}_{r} & =\left[\begin{array}{cccc}
0 & 1 & & \\
\vdots & & \ddots & \\
0 & & \ldots & 1 \\
-a_{r 1} & -a_{r 2} & \cdots & -a_{r, n}
\end{array}\right], \bar{B}_{r}=\left[\begin{array}{c}
0 \\
\vdots \\
0 \\
1
\end{array}\right], \\
\bar{C}_{r} & =\left[\begin{array}{llll}
c_{r 1} & c_{r 2} & \cdots & c_{r, n}
\end{array}\right]
\end{aligned}
$$

として記述され， $\left(\bar{C}_{r}, \bar{A}_{r}\right)$ は可観測対, 制御対象の伝達関数 は原点に零点を持たないとする。
つぎに，所望のノッチフィルタの状態空間モデルを，

$$
\left\{\begin{array}{l}
\dot{x}_{F}(t)=A_{F} x_{F}(t)+B_{F} v(t) \\
u(t)=C_{F} x_{F}(t)+D_{F} v(t)
\end{array}\right.
$$

とする.ただし， $x_{F}(t) \in R^{2}, v(t) \in R$ ，また各係数行列は

$$
\begin{aligned}
& A_{F}=\left[\begin{array}{cc}
0 & 1 \\
-\omega_{0}^{2} & -2 \zeta_{0} \omega_{0}
\end{array}\right], B_{F}=\left[\begin{array}{c}
0 \\
\omega_{0}^{2}
\end{array}\right], \\
& C_{F}=\left[\begin{array}{cc}
0 & \frac{2}{\omega_{0}}\left(\zeta_{1}-\zeta_{0}\right)
\end{array}\right], D_{F}=1
\end{aligned}
$$

として記述する.また， $\omega_{0}(>0)$ はノッチフィルタの中心角 周波数, $\zeta_{0}(>0) ， \zeta_{1}(>0)$ は共にノッチフィルタの減衰係 数である. 制御量 $y_{r}(t)$ と目標ステップ入力 $r(t)$ との偏差を $e(t)=y_{r}(t)-r(t)$ として, 以下のような拡大系を構成する.

$$
\begin{aligned}
& \left\{\begin{array}{l}
\dot{x}_{s v}(t)=A_{s v} x_{s v}(t)+B_{s v} v(t) \\
y_{s v}(t)=C_{s v} x_{s v}(t)
\end{array}\right. \\
& x_{s v}(t):=\left[\begin{array}{lll}
\dot{x}_{r}(t)^{T} & \dot{x}_{F}(t)^{T} & e(t)^{T}
\end{array}\right]^{T} \\
& A_{s v}=\left[\begin{array}{ccc}
\bar{A}_{r} & \bar{B}_{r} C_{F} & O_{n \times 1} \\
O_{2 \times n} & A_{F} & O_{2 \times 1} \\
\bar{C}_{r} & O_{1 \times 2} & 0
\end{array}\right], \\
& B_{s v}=\left[\begin{array}{c}
\bar{B}_{r} D_{F} \\
B_{F} \\
0
\end{array}\right], C_{s v}=\left[\begin{array}{lll}
\bar{C}_{r} & O_{1 \times 2} & 0
\end{array}\right]
\end{aligned}
$$

ただし， $\left(A_{s v}, B_{s v}\right)$ は可制御対であるとする，さて，サーボ 系としては状態フィードバック制御則

$$
\begin{aligned}
& v(t)=-K x_{s v} v(t)
\end{aligned}
$$

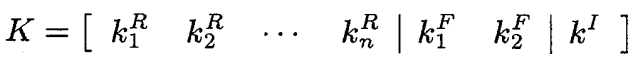

により，閉ループ極の極配置が可能となる.しかし，ノッチ フィルタの特性は $k_{j}^{F}(j=1,2)$ により变化し, 主共振モード が除去できない問題が生じる. そこで, 所望の周波数特性が 実現されるような極配置を考える。

\section{3 閉ループ系の解と係数の関係}

2 章の問題を解決するため, (5) 式において, 予め $k_{j}^{F}(j=1$ ,2)=0 とし, フィードバックゲインによるノッチフィルタ の特性劣化を防ぐ.このとき， $A_{s v}-B_{s v} K$ の特性多項式は

$$
\operatorname{det}\left(s I_{n+3}-A_{s v}+B_{s v} K\right)=s^{n+3}+\sum_{l=1}^{n+3} \alpha_{l-1} s^{l-1}
$$




$$
\begin{aligned}
& \alpha_{i}=\left(\omega_{0}^{2} c_{r, i+1}+2 \omega_{0} \zeta_{1} c_{r, i}+c_{r, i-1}\right) k^{I}+a_{r, i-2} \\
&+k_{i-2}^{R}+2 \omega_{0}\left(\zeta_{0} a_{r, i-1}+\zeta_{1} k_{i-1}^{R}\right)+\omega_{0}^{2}\left(a_{r, i}+k_{i}^{R}\right), \\
& a_{r, j}=0 \quad(j \leq 0, n+2 \leq j), \quad a_{r, j}=1 \quad(j=n+1), \\
& k_{j}^{R}=0 \quad(j \leq 0, n+1 \leq j), \quad c_{r, j}=0 \quad(j \leq 0, n+1 \leq j)
\end{aligned}
$$

である.ここで，極配置条件を考える．所望のノッチフィルタ の極を配置するための状態フィードバックゲインが $k_{j}^{F}(j=1$ ,2) =0 として与えられているので, 二つの閉ループ極 $\lambda_{1}, \lambda_{2}$ が安定となる必要がある。そこで, 所望の特性多項式を

$$
\begin{aligned}
& s^{n+3}+\sum_{l=1}^{n+3} \gamma_{l-1} s^{l-1}= \\
& \left(s+\lambda_{1}\right)\left(s+\lambda_{2}\right)\left(s^{n+1}+\beta_{n} s^{n}+\cdots+\beta_{1} s+\beta_{0}\right)
\end{aligned}
$$

とし, 残りの未知変数 $k_{1}^{R} \cdots k_{n}^{R}, k^{I}$ との関係式を求める。 (6) 式の係数 $\alpha_{i}(i=0,1, \cdots n)$ と係数比較すると以下のような 関係式が成り立つ。

$$
\Sigma_{a l} K_{a l}=\gamma_{a l}^{\prime}
$$

$$
\begin{aligned}
& \Sigma_{a l}=\left[\begin{array}{ccccc}
0 & \cdots & & 0 & \eta_{0} \\
\omega_{0}^{2} & 0 & & & \eta_{1} \\
2 \omega_{0} \zeta_{1} & \omega_{0}^{2} & & \vdots & \vdots \\
1 & 2 \omega_{0} \zeta_{1} & \ddots & 0 & \eta_{i} \\
O & \ddots & \ddots & \omega_{0}^{2} & \vdots \\
& & & 2 \omega_{0} \zeta_{1} & \eta_{n+1} \\
& & & 1 & \eta_{n+2}
\end{array}\right] \\
& \eta_{i}=\omega_{0}^{2} c_{r, i+1}+2 \omega_{0} \zeta_{1} c_{r, i}+c_{r, i-1}, \\
& K_{a l}:=\left[\begin{array}{lllll}
k_{1}^{R} & k_{2}^{R} & \cdots & k_{n}^{R} & k^{I}
\end{array}\right]^{T} \text {, } \\
& \gamma_{a l}^{\prime}:=\left[\begin{array}{lllllll}
\gamma_{0}^{\prime} & \gamma_{1}^{\prime} & \cdots & \gamma_{i}^{\prime} & \cdots & \gamma_{n+1}^{\prime} & \gamma_{n+2}^{\prime}
\end{array}\right]^{T} \text {, } \\
& \gamma_{i}^{\prime}=\gamma_{i}-a_{r, i-2}-2 \omega_{0} \zeta_{0} a_{r, n-1}-\omega_{0}^{2} a_{r, n}, \\
& \gamma_{i}=\beta_{i} \lambda_{1} \lambda_{2}+\beta_{i-1}\left(\lambda_{1}+\lambda_{2}\right)+\beta_{i-2} \text {. }
\end{aligned}
$$

いま (8) 式において未知変数 $n+1$ 個に対し, 一般には方 程式が $n+3$ 個あるため，この連立方程式の解は不能である. そこで $\Sigma_{a l}$ の 2,3 行を行変換により零行列にし，拡大係数 行列の階数と $\Sigma_{a l}$ の階数を合わせることで連立方程式が解を もつようにする，その際の必要十分条件は $\gamma_{1}^{\prime \prime}, \gamma_{2}^{\prime \prime}=0$ であ る. その結果，(8) 式は以下のようになる.

$$
\begin{aligned}
& \Sigma_{a l}^{\prime} K_{a l}=\gamma_{a l}^{\prime \prime}
\end{aligned}
$$

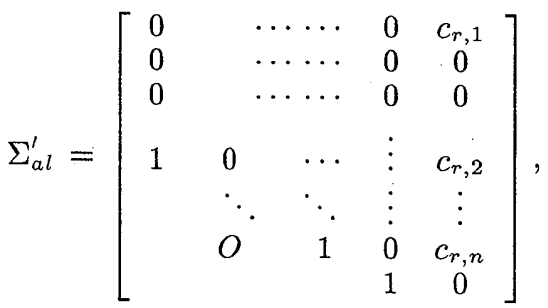

$$
\begin{aligned}
& \gamma_{a l}^{\prime \prime}:=\left[\begin{array}{lllllll}
\gamma_{0}^{\prime \prime} & \gamma_{1}^{\prime \prime} & \cdots & \gamma_{i}^{\prime \prime} & \cdots & \gamma_{n+1}^{\prime \prime} & \gamma_{n+2}^{\prime \prime}
\end{array}\right]^{T} \text {, } \\
& \gamma_{0}^{\prime \prime}=\gamma_{0}^{\prime} / \omega_{0}^{2} \text {, } \\
& \gamma_{1}^{\prime \prime}=\gamma_{i}^{\prime}-\omega_{0}^{2} \gamma_{i+2}^{\prime \prime}-2 \omega_{0} \zeta_{1} \gamma_{0}^{\prime \prime} \text {, } \\
& \gamma_{2}^{\prime \prime}=\gamma_{i}^{\prime}-2 \omega_{0} \zeta_{1} \gamma_{i+1}^{\prime \prime}-\omega_{0}^{2} \gamma_{i+2}^{\prime \prime}-\gamma_{0}^{\prime \prime} \text {, } \\
& \gamma_{i}^{\prime \prime}=\gamma_{i}^{\prime}-2 \omega_{0} \zeta_{1} \gamma_{i+1}^{\prime \prime}-\omega_{0}^{2} \gamma_{i+2}^{\prime \prime} \quad(i=2, \cdots, n+2) .
\end{aligned}
$$

(9) 式を解くと, $K_{a l}$ の各ゲインは

$$
k_{i}^{R}=\gamma_{i+2}^{\prime \prime}-\frac{c_{r, i+1}}{c_{r, 1}} \gamma_{0}^{\prime \prime} \quad(i=1 \cdots n), \quad k^{I}=\frac{\gamma_{0}^{\prime \prime}}{c_{r, 1}}
$$

のように表せる。.これにより，フィードバックゲインと所望 のノッチフィルタの特性を表すパラメータである $\left(\omega_{0}, \zeta_{0}, \zeta_{1}\right)$ との関係を示すことができる。ここで $\lambda_{1} ， \lambda_{2}$ の条件を考え る. $\gamma_{1}^{\prime \prime}, \gamma_{2}^{\prime \prime}=0$ より，それぞれ $\lambda_{1}+\lambda_{2}, \lambda_{1} \lambda_{2}$ についてまと めると

$$
\left\{\begin{array}{l}
g_{1}\left(\lambda_{1}+\lambda_{2}\right)+g_{2}\left(\lambda_{1} \lambda_{2}\right)=g_{3} \\
g_{4}\left(\lambda_{1}+\lambda_{2}\right)+g_{5}\left(\lambda_{1} \lambda_{2}\right)=g_{6}
\end{array}\right.
$$

である、ただし， $g_{1} \cdots g_{6}$ は制御対象，ノッチフィルタのパ ラメータ, $n+1$ 個の閉ループ極により構成される。(11) 式 においい, $g_{1} g_{5}-g_{4} g_{2} \neq 0$ の下で, $\lambda_{1}, \lambda_{2}$ 注以下のように なる。

$$
\lambda_{1}+\lambda_{2}=\frac{g_{5} g_{3}-g_{2} g_{6}}{g_{1} g_{5}-g_{4} g_{2}}, \quad \lambda_{1} \lambda_{2}=\frac{-g_{4} g_{3}+g_{1} g_{6}}{g_{1} g_{5}-g_{4} g_{2}}
$$

\section{4 設計手順}

設計手順を以下に示す。

1. 所望のフィルタパラメータ $\omega_{0}, \zeta_{0}, \zeta_{1}$ を与える.

2. 制約付蕉ニュートンアルゴリズムを用いて, $n+1$ 個の 安定な閉ループ極を与え, $\beta_{0} \cdots \beta_{n}$ を計算し, (12) 式 より $\lambda_{1}, \lambda_{2}$ を求める.

3. 閉ループ極が所望の範囲に入らなければ手順 2 に戻る. 4. (10) 式により, $k_{1}^{R} \cdots k_{n}^{R}, k^{I}$ を求める.

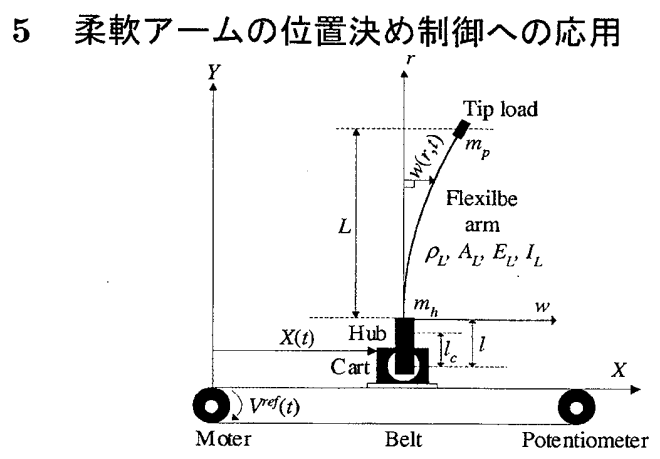

Fig.2 Model of one-link flexible arm

Fig.2 に示す直動型 1 リンク・フレキシブル・アームをモ デルとする．ただし，フレキシブルアームは Bernoulli-Euler 梁であると仮定する，さらに，根元はハブで固定され，先端 には荷重を有し，台車の位置のみ測定可能とする．設計モデ ルには, 剛体モードの夕を考慮した線形な 1 入力 1 出力の運 動方程式を用いる. 物理パラメータについては文献 (2) を参 照されたい.

\section{6 おわりに}

本稿では，ノッチフィルタを用いたサーボ系設計において， フィードバックゲインを求める連立方程式の解が不能となる問 題を解決し，㛜密に極配置が可能となる設計手法を提案した. なお，シミュレーション結果などについては当日発表する.

\section{文献}

（1）森田良文，他，“周波数依存型最適サーボ系によるフレ キシブル倒立振子の位置決め制御”，日本機械学会論文 集 (C 編), Vol.65, No.633, pp.1816-1822 (1999)

(2) 森貴彦，他，“ノッチフィルタを用いた最適サーボ系に よる柔軟構造物の振動制御”, 計測自動制御学会論文集, Vol.44, No.7, pp.611-613 (2008) 